kindly furnished me with a few notes taken by him at different times.

"In 1872 the patient suffered from gastric trouble (gastrodynia); cured. In 1884 she first complained of pain, though slight, in the abdomen. On Nov. 11th 1887, there was return of pain in the right hypochondrium, at times severe; sick once; pulse 84 ; tenderness at epigastrium; thickness over pyloric end of stomach; no hæmatemesis. This was very irregular, and she became much better the day before her death, entertaining a large party at her house, at which she was cheerful, and danced.

\section{RECTAL CONCRETION.}

BY W. J. Tyson, M.D., F.R.C.S.Eng.

There are one or two points besides those mentioned by Dr. Ingleby-Mackenzie in connexion with the above subject which I think are worth recording.

When the constipation has lasted for a few days an apparent diarrhœa may come on; and this symptom is apt to mislead one in the diagnosis of the case, unless the abdomen and rectum be examined. The above class of case resembles very much that of incontinence of urine, the result of distended bladder. There is a distended viscus in both, there is an overflow in both, and also in both there is often abdominal pain, due in the one to the stretching of the bladder, and in the other to peristaltic action. In the case of the bowel distention, opium, if given, still further mystifies the position. As a rule, aperients and injections will fail in the cases I am describing, the former only jamming up the rectum still more, and the latter fails to get any hold in the bowel, and so returns almost immediately, or the nozzle gets pluggerl with fæces on its introduction. The treatment is: Dislodge the lumps (made harder by the diarrhcea) with fingers or spoon, followed by an injection.

\section{A CASE OF EMPYEMA.}

Bx Dafid Llewellyn, L.R.C.P.L., M.R.C.S.

ON March 12th, 1887, I was called to see a child, Edgar M - , aged two years and five months, whom I found to be suffering from left pleuro-pneumonia. The temperature ranged from $103^{\circ}$ to $10 t^{\circ}$ until the eighth day, when it fell to $99^{\circ}$. On examining the chest at the expiration of this time, dulness was very pronounced up to a line drawa horizontally an inch and a half above the angle of the scapula; and on auscultating over this region the respiratory sounds were exceedingly weak, above the line very harsh, and the percussion note somewhat hyperresonant. The apex of the heart was displaced to the right side to the extent of an inch and a half. In spite of medicinal treatment the fff asion gradually rose, until at the end of a month it reached a level a little below the spine of the scapula, and the greater portion of the heart became displaced to the right of the sternum. There now appeared a suall fluctuating $\mathrm{s}$ welling over the third intercostal space, an inch external to the costal cartilages. I arquainted the parents that nothing could be done except to operate, to which they had a great aversion. At last they consented. I made a free incision into the tumour, and let out a large quantity of pus, at the same time placing the child in the prone position so as to accelerate its exit, then placing four inches of split drainage tuhe into the cavity. The wound was dressed with lint snaked in carbolic acid ( 1 in 40 ); over this ortre placed several layers of ordinary absorbent wool, and finally a flinnel bandage. The dressings were chenged three times a day for the first week, and afterwards night and morning. The child now began to take more nourishm-nt, and asked for his tojs. The physical sigus improved; absolute dulness gave way to partial resowance, and breath sourds were to be heard over the previous dull area, evidantly showing that the lung was gradually expanding. Friction sounds were very audible all over the lower part of the affected side, and the fingers became clubbed, but not the toes. I gradually shortened the drainage tube, aud abour. two minths frow the operation rumoved it altogether, laving a sinus discharying a small quantity of thin pus. Uufortunately, a few wetks afterwards I discovered that the chest had begun to fill again
I therefore determined to open up and enlarge the sinus, and put in as large a drainage tube as the space between the ribs would allow. With the assistance of my friend Dr. Thurstan, who kindly gave the anæsthetic, I made an incision two inches in length parallel with the upper border of the fourth rib, cutting through the pectoral and intercostal muscles into the thoracic cavity. About a pint and a half of fetid pus escaped, and the pleural cavity was well washed out with a warm saturated solution of boracic acid Five and a half inches of drainage tube were inserted. The wound was dressed in the same manner as in the previous operation. The subsequent treatment consisted in washing the cavity out twice a day with the aforesaid solution and the gradual shortening of the tube. Half-drachm doses of syrup of iodide of iron in water were ordered three times a day and a diet of milk, beef-tea, and mutton broth, with a little stimulant. He made an uninterrupted recovery, and eight weeks afterwards the little fellow was convalescent and running about. The lung appears to have fully expanded.

\section{A duttiruox \\ or}

\section{H OSPITAL PRACTICE, BRITISH AND FOREIGN.}

Nulla autem est alia pro certo noscendi via, nisi quamplurimas et mor borum et dissectionum historias, tum aliorum tum proprias collectas habere, et inter se comparare.-MorgaGNI De Sed. et Caus. Morb., lib. iv. Procemium.

\section{ST. THOMAS'S HOSPITAL.}

CARIES OF THE FIFTH IUMBAR VERTEBRA, LEADING TO CHRONIC RECTAL OBSTRUCTION, WITH EXTENSIVE DESTRUCTIVE ULCERATION IN THE PERINEUM ; REMARTS

(Under the care of Mr. G. H, MAKINS.)

THE following case seems of importance as illustrating the well-known difficulty in diagnosing $d$-sease of the lower lumbar vertebræ, aud from the somewhat unusual manner in which it led to rectal obstruction.

E. R-, aged thirty-seven, married, was admitted on Aug. 18th, 1887. She has had seven children, five of whom are still living, and three miscarriages. Father living and healthy; mother bedridden from paralysis; brothers and sisters healthy. The patient has always enjoyed fair health; she, however, had an attack of pleurisy tleven years ago. With the exception of the history of miscarriages, no evidence of syphilis was obtained. Her present illness commenced fifteen months before admission with the development of two small hæmorrhoids; these gave rise to pain and bæmorrhage in connexion with detecation, and one month later they were removed. The operation gave no relief; a discharge of pus and blood continued from the rectum, and a largy ischio-rectal abscess formed in the left fossa, which was opened four months after the commencement of the symptoms. Since that time the wound continued steadily to increase superficially by ulceration, and at the end of ten months she was admitted into the Lock Hospital suffering from diarrhoea, and wirh a considerable ulcer around the anus. She was there treated somewhat energetically on the supposition of syphilis, but no improvement was obtained, although she was brought fully under the influence of mercury. She lost flesh steadily during her stay there, very rapidly during the last two months, and was discharged as incu.able.

State on admission. - Extreme emaciation and feebleness. pulse 90 , ouly just perceptible ; temperature subnormal, $97 \cdot 6^{\circ}$; gums sporgy; constant painful diarrbce, detecation being involuntary. She lies belplessly on her back; the lower extremities are swollen and oedematous, especially the left; and there is a small quantity of free fluid in the abdominal cavity. The superficial abdominal veins are much distended, butno internal tumour can be discovered. Urine: sp. gr. 1016, clear, acid, no al humen. Thoracie viscera healthy. On examination of the perineum, an extensive ulcer was reen, reaching posterurly hevond the tip of the coccyx, laterally to within an inch of the 1schial tubernsities, anteriorly d+sirojing the lower inch of the posterior vaginal wall; at the deepest part 